\title{
Procedimentos favoráveis ao desenvolvimento de uma criança com Síndrome de Down numa classe comum ${ }^{1}$
}

\author{
Kátia Patrício Benevides Campos* \\ Rosana Glat**
}

\section{Resumo}

$\mathrm{Na}$ dimensão do contexto escolar, a Educação Inclusiva traz importantes reflexôes exigindo o repensar das compreensôes e práticas sobre o processo ensino-aprendizagem, objetivando o processo de socialização, desenvolvimento cognitivo, econômico, cultural e psicossocial de todos os indivíduos. Nesta perspectiva, este artigo apresenta um recorte de uma pesquisa que investigou a concepção de ensino-aprendizagem e as práticas pedagógicas de uma professora na relação com uma criança com Síndrome de Down, incluída em uma classe comum. Através da metodologia da pesquisa-ação, com base em um estudo de caso tipo etnográfico, buscamos, junto à professora, procedimentos favoráveis ao desenvolvimento social, afetivo e cognitivo da aluna. A partir das novas práticas pedagógicas introduzidas, foram evidenciadas, mudanças no comportamento e no lugar de sujeito na escola da menina, que passou a ter maior visibilidade perante a professora e os colegas, o que lhe possibilitou participação em atividades e açóes mais independentes. Foram verificadas, entretanto, ambiguidades por parte da professora, que nem sempre demonstrava acreditar no potencial de aprendizagem da aluna, embora reconhecesse seu progresso. Muitos dos dilemas, vivenciados por esta docente, se devem, entre outros aspectos, à ausência de formação específica para lidar com alunos com deficiência intelectual, bem como aos padrốes homogeneizadores de ensino, currículo e avaliação.

Palavras-chave: Deficiência intelectual; Inclusão escolar; Pesquisa-ação.

* Professora doutora da Universidade Federal de Campina Grande, Campina Grande, Paraíba, Brasil.

** Professora doutora da Universidade do Estado do Rio de Janeiro, Rio de Janeiro, Rio de Janeiro, Brasil. 


\title{
Favorable procedures to the development of a child with Down Syndrome in a common class
}

\begin{abstract}
At the size of school context, inclusive education brings important considerations requiring a rethinking of understandings and practices of the teaching-learning process aiming the course of socialization, cognitive, economic, cultural and psychosocial development of all individuals. By this perspective, this paper presents a fraction of research, which has investigated a teacher's teaching-learning conception and the pedagogical practices of her relation with a Down Syndrome child, included in a regular classroom. Through the use of the action-research methodology, and based on an ethnographic type case study, we searched, with the teacher, favorable procedures to enhance the student's social, affective and cognitive development. By the means of new pedagogical practices introduced it was possible to record changes in the child's behavior as well as in the subjective place that she occupied at school, as much as she acquired more visibility in face of her teacher and classmates, which, in turn, allowed her to engage and participate more in activities and independent actions. There were verified, however, ambiguities from the part of the teacher, who didn't always demonstrated belief in the student's learning potential, in spite of acknowledging her progress. Several of her dilemmas can be traced to, among other aspects, the lack of specific formation to deal with intellectual handicapped students, as well as the homogenizing patterns of teaching, curriculum and evaluation.
\end{abstract}

Keywords: Intellectual disability; School inclusion; Action-research.

\section{Introdução}

A Educação Inclusiva preconiza a garantia do espaço, acesso e permanência na escola para os indivíduos com deficiência, como todos os demais. Tal perspectiva implica na criaçấo de mecanismos de trabalho considerando o espaço escolar, o conteúdo programático, os ritmos de aprendizagem, uma melhor formaçáo do professor, bem como todos os recursos que favoreçam um melhor processo educacional (PLETSCH, 2009; GLAT; BLANCO, 2007; FIGUEIREDO, 2002). Nas palavras de Figueiredo,

\begin{abstract}
Inserir na escola aqueles que dela foram excluídos, sem que esta seja redimensionada dentro de um novo paradigma, é dar continuidade ao movimento de exclusão, visto que, se a escola permanece com práticas excludentes e concepçóes político-pedagógicas conservadoras, esses alunos serão excluídos ou permanecerão sem obter nenhum sucesso em sua aprendizagem e no seu desenvolvimento. (FIGUEIREDO, 2002, p. 68).
\end{abstract}

Nesse contexto, é primordial a desconstrução de práticas pedagógicas conservadoras, que colaboram para a discriminação dos indivíduos com deficiência. 
Diante do exposto, este trabalho analisa procedimentos favoráveis ao desenvolvimento social, afetivo e cognitivo de uma criança com Síndrome de Down, incluída no ensino comum. Consistiu em conjunto de procedimentos pedagógicos, acordados e implementados pela professora da turma com a aluna, desenvolvidos no contexto de uma pesquisa-ação concebida a partir de dados obtidos em um estudo etnográfico.

A metodologia de pesquisa-ação compreende três aspectos importantes: a tomada de consciência de determinada realidade, a elaboração de metas a serem atingidas para resolução de problemas e a produção de novos conhecimentos (THIOLLENT, 2009). Em outras palavras, exige o encontro de uma situação, suscitando uma investigação como modo de elaboração de uma prática a ser conduzida e/ou implementada, descrita e avaliada enquanto processo de mudança. Para isso, fez-se necessário a apropriação de conhecimentos que pudessem contribuir com a investigação (GLAT; PLETSCH, 2011; PLETSCH; GLAT, 2011; OLIVEIRA, 2008; SUPLINO, 2007; PIMENTA, 2006; TRIPP, 2005).

A pesquisa-ação teve duração de um ano letivo, tendo natureza cooperativa, na medida em que a professora trabalhou como parceira do projeto, desenvolvendo as açôes propostas elaboradas pela pesquisadora e com ela acordadas.

\section{Um olhar sobre a deficiência}

Tradicionalmente, a deficiência tem sido concebida como problemas patogênicos presentes no organismo do indivíduo. Sua origem recairia no deficiente, cuja marca se encontra presente no seu corpo por meio de características físicas, por exemplo, de indivíduos com Síndrome de Down ou com distúrbios de comportamentos considerados ditos inadequados do ponto de vista dos padrôes sociais de normalidade.

Diferente deste enfoque, estudiosos (OMOTE, 2004; FONTES et al, 2007; GLAT, 2004; 2009; PLETSCH, 2009) apontam a deficiência na perspectiva de construção social, da diferença inscrita na deficiência. Evidenciada, quase sempre, pelo sujeito considerado incapacitante, passa a ser um fenômeno produzido socialmente. Importante ressaltar que não se trata de desconsiderar os problemas gerados pelas condiçóes orgânicas, mas de reconhecer o modo como o sujeito com deficiência é visto socialmente. É preciso compreender que um melhor desempenho da capacidade e da adaptaçáo do deficiente na sociedade não depende, exclusivamente, de fatores orgânicos, e sim sociais. É na sociedade que o deficiente é produzido mediante estigmas, os quais colaboram para seu estatuto de deficiente, ou seja, aquele considerado incompetente e improdutivo (GLAT, 2009). Assim, reafirmamos que os desafios vivenciados pelos indivíduos com deficiência intelectual decorrem, em grande parte, dos perversos processos sociais de estigmatizaçáo que eles sofrem. Isto ocorre quando a cultura e seus membros mais experientes invisibilizam e paralisam o sujeito com deficiência, dificultando o desenvolvimento das funçóes psíquicas superiores, a exemplo da apropriação da língua escrita como prática cultural (ANDERSON; TEALE, 1987). 
Com base nessa compreensão, focamos nas possibilidades de aprendizagem e desenvolvimento da aluna com Síndrome de Down.

\section{A aluna com Síndrome de Down}

O sujeito focal deste estudo é uma menina com Síndrome de Down, a qual chamamos de Isabel ${ }^{2}$. Na época da coleta de dados, ela tinha sete anos, e frequentava uma turma comum de Educaçáo Infantil em uma escola da rede privada.

Como constatado, Isabel respondia algumas solicitaçóes da professora como levantar, sentar, sair da sala e, outros comandos que faziam parte da rotina da turma e da escola. Conseguia imitar, com dificuldade, quando solicitada pela professora e/ ou pelos colegas. Através de gestos, demonstrava sentimentos de alegria, irritaçáo, satisfação e a compreensão de situaçóes, quando dirigidas diretamente a ela.

É importante mencionar que, por ocasião da pesquisa, em 2010, Isabel estava há quatro anos nesta escola, permanecendo, desde que entrou, na mesma classe, Jardim I, apesar de estar acima da faixa etária dos demais alunos. De acordo com a coordenadora e a professora, sua mãe não concordava em mudá-la de turma. Além disso, ambas alegaram que Isabel não havia avançado no aprendizado didático-pedagógico correspondente às exigências referentes ao Jardim I.

Apresentamos alguns dados colhidos em estudo etnográfico que precedeu a pesquisa ação, ilustrando a vivência de Isabel na escola, destacando algumas açôes e o modo como se relacionava com as pessoas e consigo mesma. Isabel:

a) Entendia comandos como: ir ao recreio e ao banheiro, hora de levantar, de lanchar e sentar;

b) Não interagia espontaneamente com os colegas na sala de aula e no recreio;

c) Derrubava no chão qualquer objeto que estivesse a sua frente (lápis, caderno, atividade, brinquedos), rasgando os papéis que encontrava e, quando tinha oportunidade, pegava os que encontrava na mesa. Repetia a mesma ação com o lanche dos colegas;

d) Sorria e se expressava através de sons quando seus colegas faziam barulho nas brincadeiras de sala de aula;

e) Demonstrava indiferença com a presença da pesquisadora na sala de aula;

f) Chupava o dedo polegar com frequência (chupava duas a cinco vezes por observação, com a duração de dois a quatro minutos);

g) Permanecia a maioria do tempo sem ocupação, sentada em seu lugar e não reclamava (CAMPOS, 2012).

Como constatado nas observaçóes realizadas, a menina demonstrava através de gestos, sentimentos de alegria, irritação, satisfação, bem como compreensão de algumas vivências. Isabel apresentava, porém, dificuldades em acompanhar as mesmas 
solicitações em diferentes situações como: guardar os lápis dentro da caixa de lápis, se esta caixa não estivesse no lugar usual dentro da sala. Ela não compreendia que a caixa de guardar o lápis era a mesma caixa da sala, demonstrando não generalizar as açóes.

A seguir, analisaremos o processo de inclusão escolar de Isabel, durante o desenvolvimento da pesquisa-ação e a mudança de atitude e açóes da professora.

\section{A inclusão escolar mediada pela aprendizagem procedimentos}

A partir do incentivo à professora para realizaçáo de novos procedimentos pedagógicos, pode-se constatar que Isabel começou a modificar seu comportamento e a sua maneira de ser na classe, como por exemplo: a) passou a comer sozinha, diminuindo a dependência da professora; b) manipulava mais apropriadamente os objetos da sala de aula e de outros espaços da escola como papel, lápis e brinquedos; c) começou a ser chamada pelo nome com mais frequência, tanto pela professora como pelos colegas; d) atendia ao que era pedido pela professora, como entrega de material da sala a mesma; e) chegou a participar de alguns momentos de dinâmicas, brincadeiras e festas da escola.

À guisa de ilustração, trazemos relatos que mostram momentos de intervenção da professora e o modo como Isabel reagiu a cada nova situação. Conforme mencionado, embora Isabel já frequentasse a escola, antes de nossa intervençáo, era muito comum, via de regra, não participar dos acontecimentos diários.

A professora convidou Isabel para participar da música que antecede o lanche. Insistiu para que dançasse junto com os colegas fazendo os gestos representativos da música. "Vamos Isabel! Cante: bate palmas e bate o pé, pé!" (a professora cantou o trecho da música).

Segurou na sua mão ajudando-a nos movimentos. Isabel se deixou levar pela professo$\mathrm{ra}$, chegando a bater o pé, mesmo que timidamente, sem entrar no ritmo dos colegas, não acompanhando a turma. O olhar de Isabel pareceu vago, sem entender muito, demonstrando ser algo novo para ela embora todos os dias, naquele momento, estivesse presente. Costumava lanchar antes dos colegas e näo participava do ritual do lanche, mas permanecia quieta näo demonstrando interesse no lanche dos colegas (Registro em diário de campo).

A professora ensinou a Isabel tomar o iogurte sozinha. Para isso, fez uma pequena abertura no pote e convidou-a para aprender a tomá-lo dizendo: - "Vamos Isabel aprender a tomar o seu iogurte! Tia vai ensinar... Hum...! gostoso!"

Pegou na mão de Isabel e ajudou-a a segurar o pote, fazendo o movimento de beber, ensinando-a também, a inclinar a cabeça para que pudesse beber todo o líquido. Mesmo com dificuldade, Isabel assim fez. Após o iogurte, a professora falou a Isabel que comesse suas bolachas. Isabel comeu sozinha (Registro em diário de campo).

Os registros acima destacam momentos significativos para Isabel: aprender os significados da música, dos gestos que introduziam o momento do lanche e comer 
sozinha. Nossa intervenção com a professora foi no sentido de facilitar que ela entendesse que era preciso ajudar Isabel a construir o significado de suas açôes, de modo que, aos poucos, pudesse participar melhor das experiências que a cercavam e, cada vez mais, conquistar autonomia.

No primeiro momento, verificamos que, mesmo com dificuldade para acompanhar o ritmo da música e articulá-lo com gestos, Isabel começou a se envolver na atividade imitando seus colegas. Como não era acostumada a participar desse momento, demonstrava, através do seu corpo, que estava aprendendo a gesticular semelhante aos colegas. Esse tipo de situação remonta o início do desenvolvimento da criança quando a ação predomina sobre o significado, que não é completamente compreendido por ela. A esse respeito, Vygotsky ressalta:

\begin{abstract}
Tem-se mostrado que crianças, ao brincar de comer, realizam com suas máos açóes semiconscientes do comer real, sendo impossíveis todas as açóes que náo represente o comer. [...] Uma criança não se comporta de forma puramente simbólica no brinquedo; ao invés disso, ela quer e realiza seus desejos, permitindo que as categorias básicas da realidade passem através da sua experiência. A criança, ao querer, realiza seus desejos. Ao pensar, ela age. As açóes internas e externas são inseparáveis: a imaginação, a interpretação e a vontade são processos internos conduzidos pela açáo interna. (VYGOTSKY, 2003, p. 132).
\end{abstract}

Anteriormente, Isabel lanchava sozinha, antes dos colegas, para que a professora pudesse lhe ajudar e, nesses momentos, permanecia sempre quieta. Logo, ela não tinha oportunidade de aprender a função social da hora do lanche. Os significados mediados pela música, pela aprendizagem de regras sobre o ato de comer, a partilha e o gosto dos alimentos, ao contrário dos demais alunos, náo fazia parte de sua vivência. Ela já tinha dificuldades intrínsecas, e era privada de experiências!

Podemos considerar que as refeiçôes coletivas são momentos importantes de trocas afetivas e comemoraçóes constituindo-se, assim, em experiência cultural. Embora Isabel não falasse, atividades dessa natureza representavam situaçóes de aprendizagem, as quais precisavam ser estimuladas diariamente, de modo a repeti-las.

Através de experiências repetidas, a criança aprende, de forma não expressa (mentalmente) a planejar sua atividade. Ao mesmo tempo ela requisita a assistência de outra pessoa, de acordo com as exigências do problema proposto. A capacidade que a criança tem de controlar o comportamento de outra pessoa tornar-se parte necessária de sua atividade prática. (VYGOTSKY, 2003, p. 39).

Vygotsky (2003) revela, ainda, que quando confrontadas com situaçôes que não conseguem resolver sozinhas, as crianças acionam diversas formas para responder às dificuldades, seja solicitando ajuda a uma pessoa, seja utilizando-se da fala acompanhada da ação. Assim, 
O caminho do objeto até a criança e desta até o objeto passa através de outra pessoa. Essa estrutura humana complexa é o produto de um processo de desenvolvimento profundamente enraizado nas ligações entre história individual e história social. (VYGOTSKY, 2003, p. 40).

A interação de Isabel precisava ser constantemente mediada pela professora com a finalidade de oportunizá-la a aprender melhor a função social das suas açóes, dos objetos, das pessoas e das palavras, ou seja, ajudá-la a produzir significados. Nessa ótica, Newman e Holzman (2002) afirmam que o estudo da criação do significado e da atividade não deve limitar-se ao estudo das vinculaçóes entre palavras-objetos, mesmo que utilizados de modo socialmente apropriado.

Vygotsky identifica as atividades iniciais de pré-fala e pré-pensamento do bebê humano (por exemplo, balbuciar, apontar) como pré-intelectuais e pré-linguistas. [...] Muito antes o que se reconhece como 'falar', as crianças estão criando significado; estão reorganizando o ambiente determinante, que inclui elementos linguísticos. É em virtude de reorganizarem esses elementos que as crianças aprendem o uso social deles (criação de linguagem/ pensamento). Embora sons e palavras possam ser ferramentas necessárias para criação da linguagem, a criação de significado é sua precondição histórica. (NEWMAN; HOLZMAN, 2002, p. 131).

Criar condiçôes para que Isabel aprendesse a se relacionar melhor com os outros, tanto colegas ou adultos, a compreender e significar as brincadeiras e atividades da escola constituía-se uma condição essencial para o seu desenvolvimento. Durante o decorrer do trabalho da pesquisa-ação, o olhar da professora sobre Isabel passou a ser atravessado pela possibilidade de aprendizagem, mas também pela insegurança e descrença. Encontramos mudanças na representação da professora em relação a Isabel, mesmo que sua principal marca ainda fosse a síndrome de Down. Os registros abaixo, obtidos já na etapa da pesquisa-açáo, marcam uma atitude mais positiva em relação às possibilidades de aprendizagem da menina.

[...] Eu não dou mais o iogurte na colher, eu abri um pouquinho e botei na mão dela. Ela ficou segurando. Notei que ela virou a cabeça quando chegou no finalzinho do iogurte. [...] Eu achei um avanço nesse sentido (Entrevista - professora).

[...] a vasilhinha de guardar o lápis digo: “- Bota aqui!". Ela não bota. Parece pirraça (risos da professora). Agora, se eu levantar a vasilha assim, ela bota (pega a vasilha e mostra a Isabel para que entenda a ação de guardar o lápis). "- Isabel! já mandei botar dentro da vasilha!", ela não solta no chão, ela bota dentro da vasilha que eu estou segurando (Entrevista - professora).

Os dados mostram que a aluna só passou a compreender melhor o que a professora dizia após esta começar a fazer suas solicitações olhando e falando diretamente com ela. Qualquer pedido a Isabel precisava ser feito com suporte de outros recursos comunicativos, em vez de só solicitação verbal, tal como, por exemplo, apontar ou mostrar-lhe algum objeto indicador de uma ação a ser realizada. No episódio de 
guardar os lápis a professora necessitou mostrar-lhe a vasilha para que entendesse que deveria guardá-los.

É importante destacar que, além da deficiência cognitiva, Isabel também apresentava uma perda auditiva; portanto, necessitava sempre que a professora falasse olhando para ela. Quando a professora falava sem dirigir-lhe o olhar, ela não entendia o que estava sendo comunicado. Isabel necessitava de algo concreto, que qualquer pedido da professora fosse direcionado, naquele momento, somente para ela.

Vale lembrar que o trabalho com a criança com deficiência intelectual, muitas vezes, exige a retomada de um contexto ou informação, objetivando ajudá-la na habilidade de transferência de aprendizagem (MOTA ROCHA, 2002). Ou seja, é importante haver mediação para que a ação seja planejada de modo a levar a criança a compreender a atividade.

A forma como a professora orientava a menina nos chamou atenção: “- Isabel! já mandei botar dentro da vasilha?’. Ela interpretava a lentidão de Isabel em guardar os lápis como desafio, ou até mesmo teimosia. Mesmo considerando essa possibilidade, qualquer criança poderia também "desafiá-la" não atendendo seu pedido. É bem provável que a menina demorasse para guardar os lápis porque não compreendia, de imediato, a solicitação da professora. Assim, Isabel precisava de maior mediação, com o apoio do objeto da ação, ou seja, a vasilha dada ou apontada pela professora, mesmo que isso exigisse da professora ajudá-la várias vezes. Verificamos, em outro momento, um episódio semelhante:

A professora, enquanto estava vendo um livro de um aluno, mesmo sentada próxima a Isabel, pediu para que a entregasse um giz cera que estava com ela. Isabel olhava para a professora, ao mesmo tempo, rolava o giz cera de um lado para o outro na mesa em que estava. No primeiro momento, com o semblante alheio as coisas da sala, como se somente ela estivesse ali, Isabel, por cerca de dois segundos parou de rolar o giz, olhou para a professora e continuou brincando. Somente após a professora fazer novamente o pedido olhando para ela, foi que entregou o giz cera (Registro no diário de campo).

$\mathrm{Na}$ medida em que Isabel era solicitada pela professora, ela respondia ou não, dependendo da sua compreensão no momento. Açóes que pareciam simples para outras crianças, para ela eram complexas porque o grau de interação no qual foi acostumada na escola era bem menor, como revelaram os dados obtidos no decorrer do estudo etnográfico.

Por outro lado, detectamos dificuldades da professora, agravadas pelo curto tempo que ela tinha disponível para realização da atividade com a aluna, como revela o registro a seguir.

$A$ atividade pedia a escrita da letra $O$ e pintura de objetos correspondente ao mesmo som inicial. A professora xerocopiou a atividade para Isabel e a avisou que iria fazer a atividade com ela. Segurou sua mão com o lápis e em silêncio respondeu a atividade junto com Isabel, durante 3 minutos (Registro em diário de campo). 
Muitas crianças com deficiência intelectual necessitam de um tempo maior do que as demais para processar informaçóes. A hesitaçáo, muitas vezes, aparece na resolução de questôes objetivas decorrentes das dificuldades cognitivas vivenciadas pelo indivíduo, acentuada pela ausência da troca afetiva ou intelectual com o meio social (FIGUEIREDO; POULIN, 2008). Isabel, certamente, precisava de mais mediação e tempo na atividade.

Entretanto, na medida em que o trabalho com a professora avançava, ela começou a reconhecer os avanços da aluna:

Antes, ela jogava papel no chão ou amassava. Tudo que eu dava a ela, ela amassava. Agora ela já deixa as folhas no lugar... Se eu puser na minha cadeira ela não pega. Se eu puser do outro lado ela não entrega não, mas se eu pedir "- Isabel!" - Ela entrega. [...] Ela agora fica com o lápis na máo sem botar na boca e sem jogar no chão (Entrevista - professora).

O fato de a menina permanecer com papel e lápis sem rasgar ou jogar no chão reafirma a importância da mediação para sua aprendizagem. Pode-se argumentar, como já mencionado, que sua capacidade de aprendizagem não estava limitada somente por sua condição de deficiência, mas porque não lhe eram oferecidas oportunidades de desenvolvimento tais como manipular livremente os próprios objetos da sala, como papéis ou brinquedos. Os contatos que Isabel costumava ter com o material eram limitados, aconteciam apenas quando realizava a atividade com a professora. Também era preciso explicar-lhe a funçấo social dos objetos, ajudando-a a utilizá-los. Temos que considerar, ainda que rasgar e jogar objetos no cháo talvez fosse uma forma de chamar a atenção da professora e dos colegas, na medida em que, na maior parte do tempo, era ignorada por todos.

Assim, era preciso ensinar Isabel a manipular os objetos, aprendendo sua função social para que pudesse fazer a passagem da ação para a representação. Mas, para tal, a professora tinha que ter claro o que Isabel sabia fazer sozinha, para traçar caminhos que a levassem a enfrentar novos desafios com vistas a uma nova aprendizagem.

Inicialmente, Isabel demonstrava dependência da professora para realizar a maioria das açóes na escola, inclusive, nos cuidados com sua própria higiene. Pode-se dizer, portanto, que Isabel precisava de uma mediação que a ajudasse na apreensão das significaçóes sociais.

Sob essa perspectiva, o trabalho com a criança com deficiência intelectual lançando novas ações para a criança requer uma mediação cuidadosa da professora no sentido de planejar bem a ação a ser solicitada, seja com a criança considerada normal ou com algum tipo de deficiência. Sabemos que o processo de interação com a criança acontece geralmente pela família, amigos, adultos e outras crianças, mas na escola destacamos a importância de uma interação mediada pela ação intencional por meio do planejamento (VYGOTSKY, 2003; 2010). 


\section{O desenvolvimento afetivo de Isabel}

Durante a pesquisa-ação, pudemos observar que a representação das pessoas que conviviam com Isabel na escola foi alterada, considerando que antes ela era tida pela professora e pelos colegas como "a bebezinha da sala", conforme registrado neste diálogo entre colegas da classe e a professora:

Isabel tinha rasgado uma folha que estava na mesa junto de seus colegas, e Flávio falou para Roberto que ela rasgou porque era "uma bebezinha".

Flávio diz: - "Não é, tia? Isabel não é uma bebezinha?"

A professora respondeu: - "É, ela é uma bebezinha".

Vez por outra, quando Isabel fazia algo que não era permitido, colegas referiam-se a ela como bebê (Registro em diário de campo).

Atrelado à sua condição de deficiência, tal atributo decorrente das dificuldades cotidianas de Isabel reforçava os sentimentos de superproteção e infantilização, o que, por sua vez, colaborava para uma produção de impotência, diante do que precisava aprender. Porém, em decorrência da progressiva aproximaçáo da professora e dos colegas, outras trocas afetivas foram sendo observadas, expressas por maior cuidado e crença na sua aprendizagem.

Isabel abraçou e encostou a boca no rosto de um colega que brincava com ela fazendo carícias em seus braços. (Registro em diário de campo).

Isabel sorriu porque as colegas da mesa estavam sorrindo por algum motivo que não deu para perceber. Um colega falou: - "Tia! Isabel está rindo muito". A professora respondeu que era porque ela estava muito feliz naquele dia (Registro em diário de campo).

- "Fiquei surpresa por que Maria é meio enjoadinha, um pouco difícil na sala. Tudo faz uma confusão, parece intocável, pois estava conversando e pegando na mão de Isabel. Não acreditei quando vi. Isabel ria bastante, parece que estava gostando" (risos da professora) (Entrevista - professora).

Com a transformação do tipo de interação que ocorria em classe, a professora e os colegas passaram a ver Isabel com outras possibilidades, ou seja, como uma criança que entende, que está feliz, que sorri e troca afetos. São mudanças muito significativas porque a conduzem para um lugar de sujeito capaz de participar ativamente de um mundo social. Assim, evidenciamos uma afetividade positiva dos colegas na relação com Isabel, o que, sem dúvida, contribuiu para seu desenvolvimento intelectual, uma vez que este é diretamente influenciado pela dimensão afetiva. De acordo com Wadsworth,

$\mathrm{O}$ aspecto afetivo tem uma profunda influência sobre o desenvolvimento intelectual. Ele pode acelerar ou diminuir o ritmo de desenvolvimento. Ele pode determinar sobre que conteúdos 


\begin{abstract}
a atividade intelectual se concentrará. De acordo com Piaget, o aspecto afetivo, em si, náo pode modificar estruturas cognitivas (esquemas), embora, como já vimos, ele pode influenciar quais estruturas modificar. [...] Para Piaget, o aspecto afetivo não mais predeterminado do que a inteligência, propriamente dita. $\mathrm{Na}$ sua visão, há notável paralelo entre aspectos afetivo e cognitivo. Primeiro, o afeto se desenvolve no mesmo sentido que a cognição ou inteligência. [...] À medida que os aspectos cognitivos se desenvolvem, há um desenvolvimento paralelo da afetividade. (WADSWORTH, 1993, p. 23).
\end{abstract}

Afeto inclui sentimentos e expressóes representativos do desenvolvimento intelectual. Assim, os sentimentos atribuídos à Isabel foram motivadores para que agisse diante dos objetos e das pessoas (WADSWORTH, 1993; CHARLOT, 2000). Embora ainda de forma tímida, os relatos acima apontam que Isabel evoluiu nas suas interaçóes, evidenciadas pela mudança de comportamento, tanto dela própria quanto dos que com ela interagiam (seus colegas e a professora).

Acreditamos na motivação da atividade intelectual como fator impulsionador da aprendizagem. É preciso acioná-la objetivando o esforço a ser desenvolvido em cada momento. Nesse processo, a afetividade está presente por meio da seleção que se dá na atividade intelectual quando o sujeito, na ação, seleciona objetos ou eventos particulares. "[...] Esta seleção não é provocada pelas atividades cognitivas, mas pela afetividade [...]” (WADSWORTH, 1993, p. 22).

Percebemos o sentimento dos colegas em relação à Isabel, e a consequente maior aproximação da menina com o grupo deveu-se, sem dúvida, à mudança de atitude da professora, que passou a lhe dar mais atenção. Em outras palavras, a professora foi modelo para a transformaçáo na atitude dos colegas, que começaram a interagir mais com Isabel, seja brincando ou auxiliando-a, como nos exemplos abaixo.

Flávio percebeu que Isabel estava com sede e perguntou se queria água. Isabel deixou Flávio pegar sua mamadeira para botar a água. Ao voltar com a água Isabel sorriu para Flávio. (Registro em diário de campo).

Laura tomou o lápis de Isabel que contestou mexendo as mãos, fazendo murmúrios. Laura escreveu no papel a letra O e falou: - "Oh Isabel, está vendo? é a letra O”. Isabel olhou todo o momento para Laura e sorriu (Registro em diário de campo).

A importância da mediação da professora, a qual foi, de certa forma, reproduzida pelos colegas, deu-se na mudança das interaçôes com Isabel. Mesmo que os conteúdos trabalhados na sala de aula não tenham sido apreendidos por ela, era fundamental para seu desenvolvimento a continuidade da sua participação das atividades na escola junto ao seu grupo.

Pois, a aprendizagem acontece por meio do objeto do conhecimento através das relaçôes humanas, ou seja, "[...] para chegar ao objeto, é necessário que o sujeito entre em relaçáo com outros sujeitos que estão, pela funçáo social que lhe atribuem, constituindo esse objeto enquanto tal” (KLEIN, 1996, p. 94). Não podemos esque- 
cer que a aprendizagem se dá na interação social com o outro, quando nos apropriamos dos objetos culturais, por meio dos conhecimentos, que comportam significados e sentidos. $\mathrm{Na}$ experiência vivenciada, a dimensão afetiva confere importância ao objeto internalizado, razáo pela qual o processo de internalização compóe-se de aspectos cognitivos e afetivos.

\section{Considerações finais}

Considerando que a pesquisa-ação permite o diálogo permanente com os sujeitos participantes e que as açôes não são definidas a priori, mas vão se dando ao longo do processo, durante o decorrer do estudo fomos redefinindo procedimentos e agregando novos modos de intervir com Isabel. Assim, a pesquisa-ação procurou conhecer o cotidiano da escola e participar apreendendo o modo como era conduzida as atividades escolares (THIOLENT, 2009).

Constatamos mudanças em Isabel com relação ao seu próprio lugar de sujeito na escola, uma vez que começou a ter maior visibilidade perante a professora e os colegas. Vale lembrar que, antes da intervenção, Isabel tinha menos autonomia na sala de aula.

Podemos dizer que Isabel avançou no seu desenvolvimento social e afetivo, demonstrando maior interação com os colegas, e a professora expressa por gestos e açóes o que indica maiores possibilidades de aprendizagem para a menina. Nesse processo, verificamos ambiguidades da professora, pois ora demonstrava acreditar na sua mediaçáo mais efetiva com Isabel, comentando descobertas da menina, ora demonstrava desânimo, expondo as dificuldades de Isabel no tom de descrença.

Considerando as dificuldades da professora no trabalho mais mediado com Isabel, compreendemos que muitos dos dilemas, vividos por esta, apontados também em outras pesquisas, se deve, dentre outros aspectos, à ausência de formação específica para lidar com aluno com deficiência intelectual e, principalmente, "[...] padróes tradicionais homogeneizadores de ensino, currículo e avaliação" (GLAT; PLETSCH, 2011, p. 141).

\section{Referências}

ANDERSON, A. B.; TEALE, W. H. A Lectoescrita Como Prática Cultural. In: FERREIRO, E.; PALÁCIO, M. G. Os Processos da Leitura e Escrita: Novas Perspectivas. Porto Alegre: Artes Médicas, 1987.

CAMPOS, K. B. Isabel na Escola: Desafios e Perspectivas para a Inclusão de uma Criança com Síndrome de Down numa Classe Comum. Tese (Doutorado em Educação) - Programa de Pós-Graduação em Educaçấo. Universidade do Estado do Rio de Janeiro, Rio de Janeiro, 2012.

CHARLOT, B. Da relaçáo com o saber: elementos para uma teoria. Porto Alegre: Artes Médicas Sul, 2000.

FIGUEIREDO, R. V. Políticas de inclusão: escola-gestão da aprendizagem na diversidade. In: ROSA, D. E.G.; SOUZA, V. C. (Org.). Políticas organizativas e curriculares, educaçáo inclusiva e formaçáo de professores. Rio de Janeiro: DP\&A, p. 67-78, 2002 .

FIGUEIREDO, R. V. ; POULIN, J. Aspectos funcionais do desenvolvimento cognitivo de crianças com deficiência mental e metodologia de pesquisa. In: CRUZ, S. H. V. (Org.). A criança fala: a escuta de crianças em pesquisas. São Paulo: Cortez, p. 245-263, 2008.

FONTES, R. S. et al. Estratégias pedagógicas para a inclusão de alunos com deficiência mental no ensino regular. In: GLAT, R. (Org.). Educaçáo Inclusiva: cultura e cotidiano escolar. Rio de Janeiro: 7 Letras, 2007. 
GLAT, R. A integraçáo social dos portadores de deficiência: uma reflexáo. Rio de Janeiro: 7 Letras, 2004.

Somos iguais a vocês: depoimentos de mulheres com deficiência mental. Rio de Janeiro: 7 Letras, 2009

GLAT, R.; BLANCO, L. M. V. Educação especial no contexto da educaçăo inclusiva. In: GLAT, R. (Org.). Educaçáo inclusiva: cultura e cotidiano escolar. Rio de Janeiro: 7 Letras, 2007.

GLAT, R.; PLETSCH, M. D. Inclusão Escolar de alunos com necessidades especiais. Rio de Janeiro: EdUERJ, 2011.

KLEIN, L. R. Alfabetizaçáo: quem tem medo de ensinar. São Paulo: Cortez, 1996.

MOTA ROCHA, S. R. da. Leitores da comunidade e crianças leem histórias na escola: Programa de integração da criança remanescente à comunidade letrada. Tese (Doutorado em Educação) - Programa de Pós-Graduação de Educação, Universidade Federal do Ceará, Fortaleza, 2002.

NEWMAN, F.; HOLZMAN, L. Lev Vygotsky: cientista revolucionário. São Paulo: Loyola, 2002.

OLIVEIRA, M. C. Avaliaçáo de necessidades educacionais especiais: construindo uma nova prática educacional. Dissertação (Mestrado em Educaçâo). Programa de Pós-Graduação em Educação, Universidade do Estado do Rio de Janeiro, Rio de Janeiro, 2008.

OMOTE, S. A. Estigma em tempo de inclusão. Revista Brasileira de Educação Especial, v. 10, n. 3, p. $287-$ 308,2004

PIMENTA, S. G. Pesquisa-açáo crítico colaborativa: construindo seu significado a partir de experiências na formaçấo e na atuaçáo docente. In: PIMENTA, S. G; GHEDIN, E.; FRANCO. M. A. S. (Orgs.). Pesquisa em educaçáo: alternativas investigativas com objetos complexos. São Paulo: Loyola, p. 25-64, 2006.

PLETSCH, M. D. A formação de professores para a educação inclusiva: legislação, diretrizes políticas e resultados de pesquisas. Revista Educar, Curitiba, n. 33, p. 143-156, 2009.

.; GLAT, R. Pesquisa-ação: estratégia de formação continuada de professores para favorecer a inclusão escolar. Espaço, Rio de Janeiro, v. 33, p. 50-60, 2011.

SUPLINO, M. H. S. O. Retratos e imagens das vivências inclusivas de dois alunos com autismo em classes regulares. Tese (Doutorado em Educaçấo) - Programa de Pós-Graduação em Educação, Universidade do Estado do Rio de Janeiro, Rio de Janeiro, 2007.

THIOLLENT, M. Metodologia da pesquisa-ação. São Paulo: Cortez, 2009.

TRIPP, D. Pesquisa-ação: uma introdução metodológica. Educação e Pesquisa. São Paulo, v. 1, n. 3, 2005.

VYGOSTSKY, L. A formaçáo social da mente. São Paulo: Martins Fontes, 2003.

Aprendizagem e desenvolvimento intelectual na idade escolar. In: VYGOTSKY, L.S; LURIA, A. R.; LEONTIEV, A. N. Linguagem, desenvolvimento e aprendizagem. São Paulo: Ícone, 2010.

WADSWORTH, B. J. Inteligência e afetividade da criança da teoria de Piaget. São Paulo: Pioniera, 1993.

\section{Notas}

${ }^{1}$ Este texto representa um recorte da tese de doutorado da primeira autora, defendida no Programa de Pós-graduação em Educação da UERJ, sob orientaçấo da segunda autora.

${ }^{2}$ Todos os nomes aqui utilizados são fictícios.

\section{Correspondência}

Kátia Patrício Benevides Campos - Universidade Federal de Campina Grande, Unidade Acadêmica de Educação. Bairro Universitário, CEP: 58429-900 - Campina Grande, Paraíba - Brasil.

E-mail:katiapbcampos@hotmail.com - rglat@terra.com.br

Recebido em 10 de agosto de 2015

Aprovado em 16 de novembro de 2015

Revista Educação Especial | v. 29 | n. 54 | p. 27-40 | jan./abr. 2016

Santa Maria

Disponível em: <http://www.ufsm.br/revistaeducacaoespecial> 